\title{
The effects of varying doses of pilocarpine on the transport response in white rats
}

\author{
CHRISTOPHER WILSON and ALLISON D. CROMEY \\ Lafayette College, Easton, Pennsylvania
}

(B. H. Cohen, Sponsor)

\begin{abstract}
An experiment was performed to investigate the effects of pilocarpine on the transport response in white rats. Forty 23-day-old rats received administrations of varying doses of the cholinergic agonist and then were tested for the presence and intensity of the transport response. Results revealed a suppression by pilocarpine on the transport response, which became evident at intermediate and high doses of the drug.
\end{abstract}

In investigating age-related behavioral changes, it is necessary to consider the interaction of the various neurotransmitter systems in producing and/or modulating particular behaviors (Carlton, 1963). In the developing rat, for instance, as the dopamine systems mature, functionally related increases in behavioral arousal appear (Campbell, Lytle, \& Fibiger, 1969; Kellogg \& Lundborg, 1972; Lal \& Sourkes, 1973), along with various forms of stereotypy, including sniffing, licking, gnawing, and wall climbing (Barrett, Caza, Spear, \& Spear, 1982; Costall \& Naylor, 1973; Ernst, 1967; Lal \& Sourkes, 1973; Melzacka, Wisniowska, \& Vetulani, 1978; Reinstein, McClearn, \& Isaacson, 1978). As the animal matures, there is a decrease in the dopamine-related behavioral activation; this decrease appears to be a modulating function imposed by the development of forebrain cholinergic systems (Blozovski \& Bachevalier, 1975; Carlton, 1963; Fibiger, Lytle, \& Campbell, 1970; Moorcroft, Lytle, \& Campbell, 1971). These studies point to the conclusion that cholinergic systems appear to have a suppressive effect on dopaminergic systems with respect to behavioral activation (Campbell \& Mabry, 1973; Fibiger et al., 1970).

Brewser and Leon (1980) described a response in rat pups that helps the mother transport the pups from one location to another. The behavior is characterized by an active flexion and adduction of the hindlimbs and an extension and adduction of the forelimbs and is made in response to being orally grasped by the nape of the neck. This transport response is elicited maximally by dorsal stimulation initiated by the mother and is beneficial because it occurs when the pups are active, relatively unwieldy, and not yet self-sufficient (Brewster \& Leon, 1980). Thus, the response has ecological importance.

The development of the transport response falls within the time frame normally associated with that of behavioral

Address all correspondence to Christopher Wilson, Department of Psychology, Lafayette College, Easton, PA 18042. arousal and the development of the dopamine system, becoming first evident at about postnatal Day 8 and gradually increasing in frequency and intensity until about Day 20, at which time it begins to wane (Brewster \& Leon, 1980). The response also appears to be subserved by a dopamine system, since it can be abolished with haloperidol in 19-day-old rat pups (Wilson, Cullen, \& Sendall, 1984) and reinstated with apomorphine in 40day-old rats, animals typically too old to show an effective response (Wilson, 1985). Starting at the 3rd postpartum week, the transport response gradually decreases in intensity and is difficult to elicit by the end of the 4th postpartum week (Brewster \& Leon, 1980), a time when forebrain cholinergic systems reach functional maturity (Fibiger et al., 1970).

We recently presented a series of experiments (Wilson $\&$ Cromey, in press) that led to the conclusion that the normal suppression of the transport response at the time of weaning is due to maturation of the forebrain cholinergic systems. One experiment in that series investigated the effect of administration of varying levels of a cholinergic agonist on the ease of elicitation and intensity of the transport response in 23-day-old rats, rats that normally show a very strong transport response. We reported a statistically reliable suppression of the transport response with administration of 1.0 and $5.0 \mathrm{mg} / \mathrm{kg} / 5 \mathrm{ml}$ of pilocarpine, but no reduction at an intermediate dose, $2.5 \mathrm{mg} / \mathrm{kg} / 5 \mathrm{ml}$, of the drug. In looking at individual animals from that experiment, we noted that a high percentage of subjects at the $2.5-\mathrm{mg}$ dose level showed fairly intense response levels. At the time that study was submitted, we expressed concern for possible sources of secondary and error variance in our experimental procedure. The experiment presented here is a partial replication of the series of experiments previously presented (Wilson \& Cromey, in press) and investigates, specifically, the effect of varying levels of systemic administration of pilocarapine on the transport response. 


\section{METHOD}

\section{Subjects}

Subjects in this experiment consisted of 40 Sprague-Dawley albino rats, 23 days of age at the time of testing. Litters were derived from preterm pregnant rats purchased from Ace Animals (Boyertown, PA). Upon arrival in our laboratory, the subjects were placed in clear Plexiglas breeding cages in a room kept at $22^{\circ} \mathrm{C}$ and on a 12:12-h light:dark cycle with lights on at 0700 . During the testing phase of this experiment, all testing occurred between 1000 and $1200 \mathrm{~h}$, with each rat being tested at only one drug dosage.

\section{Materials}

Pilocarpine nitrate was purchased from Sigma Chemical Co. (St. Louis, MO).

\section{Procedure}

Each day at 0900 and $1700 \mathrm{~h}$, the cages were checked for the presence of newborn litters. All births occurred 7 to 10 days after the rats' arrival at the laboratory, and the date of birth was recorded as postpartum Day 0. On the morning of postnatal Day 1, each litter was culled to 8 to 10 pups; litters containing fewer than 8 pups were not used in these experiments. On the day of testing, the pups were separated from their mothers and placed in a litter cage containing fresh litter. They then were given intraperitoneal injections of varying doses $(0.0,1.0,2.5$, and $5.0 \mathrm{mg} / \mathrm{kg} / 5 \mathrm{ml}$ ) of pilocarpine nitrate. (Those given the $0.0-\mathrm{mg} /$ $\mathrm{kg} / 5 \mathrm{ml}$ dose were the saline control animals.) Following a 20-min postinjection delay, the pups were tested for the presence and intensity of the transport response, as described below.

Each rat was given four postdrug trials, with approximately 2-min intertrial intervals, testing for the occurrence and intensity of the transport response. The test consisted of the pup's being grasped and suspended by the skin of the nape of the neck between the thumb and first two fingers by an experimenter. The intensity of the pup's transport response was graded on a scale of 0-5 according to the schema proposed by Brewster and Leon (1980). This schema involved the awarding of one point for each forelimb, hindlimb, and/or tail that the animal brought into contact with its ventral surface. The mean of the four trials was used for statistical analyses. As a check for any gross motor impairments, at the conclusion of postdrug testing, each rat pup was given a righting response test by being placed on its back; whether the animal righted itself within $1 \mathrm{sec}$ was then recorded.

\section{Data Analysis}

The data were analyzed using standard parametric procedures, ${ }^{1}$ and subsequent comparisons between conditions were determined with Newman-Keuls tests (Kirk, 1968). Differences with a probability less than $.05(p<.05)$ were considered statistically reliable.

\section{RESULTS}

Mean transport response intensities (and standard errors) for subjects given $0.0,1.0,2.5$, and $5.0 \mathrm{mg} / \mathrm{kg} / 5 \mathrm{ml}$ of pilocarpine nitrate were $2.88(.36), 2.33(.41), 1.45$ (.27), and $1.63(.21)$, respectively. The last two figures were significantly different from that for the control condition. The data appear to show a reduction in a transport response following administration of the cholinomimetic pilocarpine. An analysis of variance performed to analyze differences in mean response intensities yielded a significant dose effect $[F(3,36)=4.32, p<.05]$. Post hoc analyses revealed a significant reduction in response intensity for rats having received 2.5 and $5.0 \mathrm{mg} / \mathrm{kg}$ pilocarpine nitrate compared with rats in the saline control condition. Across groups for this experi- ment, data indicate that a premature suppression of the transport response can be caused by stimulating the cholinergic system and that the normal suppression seen 5 to 7 days later may be a function of normal endogenous cholinergic maturation.

Finally, all the animals in this experiment were able to right themselves within $1 \mathrm{sec}$ of being placed on their backs.

\section{DISCUSSION}

Hedley and Wallach (1983) reported an attentuation of apomorphineinduced stereotypic behaviors in mice with pretreatments of the cholinomimetic pilocarpine and the anticholinesterase agent physostigmine. Likewise, Fibiger et al. (1970) reported an attentuation of amphetamine-induced psychomotor activity in 20- to 25-day-old rats following administration of pilocarpine. This experiment was designed to test the hypothesis that maturation of the cholinergic system results in a suppression of the transport response. Specifically, in this experiment 23-day-old rats were given varying doses of the cholinomimetic pilocarpine and then were tested for the presence and intensity of the transport response. It was hypothesized that if the reduction in the transport response is due to maturation of forebrain cholinergic systems, administration of pilocarpine would result in a decrease in the transport response in rats given the drug as opposed to control animals.

Data from this experiment, along with data from a previous report (Wilson \& Cromey, in press), point to the conclusion that the reduction in frequency and intensity of the transport response is due to maturation of forebrain cholinergic systems; specifically, data presented here show a reduction in response intensity with moderate to high levels of pilocarpine. We also conclude that perhaps a critical level of pilocarpine is needed to produce the response suppression and that this reduction is not due to any gross motor impairment, since all the subjects in this experiment were able to right themselves and did not appear to have any major problems of locomotion.

From a more global approach, the effect reported here may be a manifestation of a more general reduction in behavioral arousal à la Hall (1979). We have shown the transport response to be affected by manipulations of dopaminergic systems (Wilson, 1985; Wilson et al., 1984) and to be reinstated by blocking central cholinergic systems (Wilson \& Cromey, in press). It appears that some forms of general behavioral arousal induced by external stimuli are under dopaminergic control (Camp \& Rudy, 1987) and that suppression of the arousal is an effect of maturation of cholinergic systems (Fibiger et al., 1970). Comparing temporal ontogeny of the transport response with other forms of behavioral arousal and considering the probable mechanisms subserving the response, it may be that the transport response is one aspect of behavioral arousal induced by a specific external stimulus.

\section{REFERENCES}

Barrett, B. A., Caza, P., Spear, N. E., \& Spear, L. P. (1982). Wall climbing, odors for the home nest and catecholaminergic activity in rat pups. Physiology \& Behavior, 29, 501-507.

BlozovsKi, D., \& BACHEVALIER, J. (1975). Effects of atropine on behavioral arousal in the developing rat. Developmental Psychobiology, 8, 97-102.

BreWSTER, J., \& LEON, M. (1980). Facilitation of maternal transport by Norway rat pups. Journal of Comparative \& Physiological Psychology, 94, 80-88.

CAMP, L. L., \& Rudy, J. W. (1987). Behavioral activation in infant rats: Pharmacological evidence of dopaminergic mediation. Psychobiology, 15, 317-328.

Campbell, B. A., Lytle, L. D., \& Fibiger, H. C. (1969). Ontogeny of adrenergic arousal and cholinergic inhibitory mechanisms in the rat. Science, 166, 637-638. 
Campbell, B. A., \& Mabry, P. D. (1973). The role of catecholamines in behavioral arousal during ontogenesis. Psychopharmacologia, 31, 253-264.

Carlton, P. L. (1963). Cholinergic mechanisms in the control of behavior by the brain. Psychological Review, 70, 19-39.

Costall, B., \& NaYlor, R. J. (1973). The role of telencephalic dopaminergic systems in the mediation of apomorphine-stereotyped behaviour. European Journal of Pharmacology, 24, 8-24.

ERNST, A. M. (1967). Mode of action of apomorphine and dexamphetamine on gnawing compulsion in rats. Psychopharmacologia, 10, 316-323.

Fibiger, H. C., Lytle, L. D., \& Campbell, B.A. (1970). Cholinergic modulation of adrenergic arousal in the developing rat. Journal of Comparative \& Physiological Psychology, 72, 384-389.

HALL, W. G. (1979). The ontogeny of feeding in rats: I. Ingestive and behavioral responses to oral infusions. Journal of Comparative \& Physiological Psychology, 93, 977-1000.

Hedley, L. R., \& Wallach, M. B. (1983). Potentiation of apomorphine-induced gnawing in mice. Progress in NeuroPsychopharmacology \& Biological Psychiatry, 7, 47-56.

KelloGg, C., \& LUNDBorg, P. (1972). Ontogenetic variations in responses to l-dopa and monoamine receptor-stimulating agents. Psychopharmacologia, 23, 187-200.

KIRK, R. E. (1968). Experimental design: Procedures for the behavioral sciences. Belmont, CA: Brooks/Cole.

LAL, S., \& SourKes, T. L. (1973). Ontogeny of stereotyped behavior induced by apomorphine and amphetamine in the rat. Archives of International Pharmacodynamics \& Therapeutics, 202, 171-182.
Melzacka, M., Wisniowska, G., \& Vetulani, J. (1978). The distribution of apomorphine in rat brain: Possible behavioral correlates. Polish Journal of Pharmacology, 30, 335-345.

Moorcroft, W. H., Lytle, L. D., \& CAMPBell, B. A. (1971). Ontogeny of starvation-induced behavioral arousal in the rat. Journal of Comparative \& Physiological Psychology, 75, 59-67.

Reinstein, D. K., McClearn, D., \& Isaacson, R. L. (1978). The development of responsiveness to dopamine agonists. Brain Research, 150, 216-223.

WiLson, C. (1985). The effects of apomorphine and isoproterenol on the 'transport response' in the white rat. International Journal of Developmental Neuroscience, 3, 279-284.

Wilson, C., \& CromeY, A. D. (in press). Evidence of a cholinergic input into the suppression of the transport response in white rats. Psychobiology.

Wilson, C., Cullen, E., \& Sendell, K. (1984). A pharmacologic investigation of the 'transport response' in the white rat. International Journal of Developmental Neuroscience, 2, 323-329.

\section{NOTE}

1. Appropriate nonparametric statistical techniques were applied to the data as a check for the parametric statistical tests reported in the Results section. The nonparametric test results were not reported, because they were identical to the parametric statistical test results.

(Manuscript received September 14, 1988.) 